\title{
Adult Kidney Wilms Tumor
}

National Cancer Institute

\section{Source}

National Cancer Institute. Adult Kidney Wilms Tumor. NCI Thesaurus. Code C6180.

Wilms tumor of the kidney which occurs in adults. 